\title{
The clip-wrap technique in the treatment of intracranial unclippable aneurysms
}

\author{
Eberval Gadelha Figueiredo', Luciano Foroni², \\ Bernardo Assumpção de Monaco², Marcos Q.T. Gomes³, \\ Hugo Sterman Neto ${ }^{2}$, Manoel Jacobsen Teixeira ${ }^{4}$
}

\begin{abstract}
Fusiform and dolichoectatic aneurysms are challenging lesions to treat with direct clipping. Treatment of these aneurysms often requires alternative surgical strategies, including extracranial-intracranial bypass, wrapping, or clip-wrap techniques. Nonetheless, these alternatives methods of treatment have been underused and frequently overlooked. Objective: To report a series of nine cases of otherwise untreatable aneurysms managed using the clip-wrap technique and discuss its surgical nuances. Method: In the last four years, 9 cases of ruptured aneurysms treated by the clip-wrap techniques were identified in the Division of Neurological Surgery, University of São Paulo, School of Medicine. Results: The aneurysms were located at middle cerebral artery (2), anterior choroidal artery (1), anterior communicating artery (1), carotid ophthalmic (3), posterior cerebral artery (1) and posterior-inferior cerebellar artery (1). Three were dolichoectatic, 4 were unsuitable to complete surgical clipping because parent or efferent vessels arises from the aneurysm sac (1 MCA, 1 AcomA, 1 CO, 1 PICA aneurysms) and two, although ruptured aneurysms, were too small $(<2 \mathrm{~mm})$ to be directly clipped. No early or late rebleeding was observed after 2 years mean follow-up. One patient deceased due to pulmonary tromboembolism. Conclusion: Clip-wrap techniques for the treatment of fusiform and otherwise unclippable aneurysms seem to be safe and it can be associated with a low rate of acute or delayed postoperative complications. It can prevent rebleeding and represents an improvement when compared with the natural history.
\end{abstract}

Key words: aneurysms, clipping, surgical treatment, wrapping.

\section{Técnica de "clip-wrap" no tratamento de aneurismas rotos não clipáveis}

\section{RESUMO}

Aneurismas fusiformes são lesões de difícil tratamento e frequentemente necessitam de técnicas alternativas de tratamento, incluindo anastomose extra-intracranial ou técnicas de "clip-wrap". Contudo o uso destas técnicas é frequentemente esquecido e negligenciado. Objetivo: Descrever retrospectivamente casuística de nove casos de aneurismas não clipáveis tratados com a técnicas de "clip-wrap" e discutir as nuances cirúrgicas. Resultados: Revisão dos últimos quatro anos da casuística da Divisão de Clínica Neurocirúrgica do HCFMUSP mostrou que 384 casos eram de aneurismas rotos. Destes, 9 eram de aneurismas não clipáveis tratados com a técnica de "clip-wrap". Destes, 2 aneurismas eram de artéria cerebral media, 1 de artéria coroidéia anterior, 1 de artéria comunicante anterior, 3 de artéria oftálmica, 1 de artéria cerebral posterior e 1 de PICA. Três eram lesões ectásicas, 4 não puderam ser completamente clipados devido a relação de aneurismas com vasos eferentes, aferentes ou perfurantes, e dois, apesar de rotos eram

\section{Correspondence}

Eberval G Figueiredo

Rua Dr. Eneas de Carvalho Aguiar, 255

Divisão de Clínica Neurocirúrgica / $5^{\circ}$

ICHC / Hospital das Clínicas / FMUSP

05403-000 São Paulo SP - Brasil

E-mail: ebgadelha@yahoo.com

Received 17 June 2009

Received in final form 11 September 2009

Accepted 15 September 2009 pequenos demais para serem clipados $(<2,0 \mathrm{~mm})$. Sangramento precoce ou tardio não foram observados, em um seguimento médio de 2 anos. Conclusão: $A$ técnica descrita é segura e está associada com baixa incidência de complicações agudas ou tardias. Ela previne ressangramanto e representa um avanço em relação à história natural destas lesões. Palavras-chave: aneurismas, tratamento cirúrgico.

Division of Neurological Surger, University of São Paulo, School of Medicine, São Paulo SP, Brazil: 'Supervisor and Coordinator of Cerebrovascular Surgery; ${ }^{2}$ Resident; ${ }^{3}$ Coordinator of Skull Base Surgery; ${ }^{4}$ Director and Chairman. 
Fusiform and dolichoectatic aneurysms are challenging lesions to treat with direct clipping. Perforators incorporated into the aneurysmal segment frequently impede adequate clipping. Treatment of these aneurysms often requires alternative surgical strategies, including extracranial-intracranial (EC-IC) bypass, wrapping, or clipwrap techniques.

Nonetheless, these alternatives methods of treatment have been underused and frequently overlooked.

We present a retrospective study describing their casuistic of nine cases of otherwise untreatable aneurysms managed using the clip-wrap technique and discuss its surgical nuances.

\section{METHOD}

This is a retrospective study reporting the Division of Neurological Surgery, University of São Paulo, School of Medicine, experience in treating ruptured cerebral aneurysms by wrapping and clipping methods. All cases of ruptured intracranial aneurysms operated on the last four years were evaluated. In this period, 384 cases of ruptured cerebral aneurysms were treated. From those, 9 cases of ruptured aneurysms managed by the clip-wrap techniques were identified (Table). These aneurysms were considered untreatable by conventional techniques, such as direct clipping or endovascular approach, either due to their relationships with the efferent, afferent and perforators vessels or their small size. Demographical data, such as age, gender and aneurysm's site were registered (Table). Patients were followed-up in an out-patient basis and suggestive events of early and late rebleeding were investigated. One patient was excluded in the follow-up analysis due to early death secondary to pulmonary embolism. Patients and relatives have given consent for this publication.

\section{RESULTS}

Table summarizes the casusistic. Eight patients were female and one only was male, with age varying between 40-73 years (mean $=53.4$ years). The aneurysms were located at middle cerebral artery (MCA) (2), anterior choroidal artery (AchA) (1), anterior communicating artery (AcomA) (1), carotid ophthalmic (CO) (3), posterior cerebral artery (PCA) (1) and posterior-inferior cerebellar artery (PICA) (1). Three aneurysms were fusiform (1 MCA, 1 AchA, 1 PCA aneurysms), 4 were unsuitable to complete surgical clipping because parent or efferent vessels arises from the aneurysm sac (1 MCA, 1 AcomA, 1 CO, 1 PICA aneurysms) and two, although ruptured aneurysms, were too small $(<2 \mathrm{~mm})$ to be directly clipped (2 CO aneurysms). No early and no late rebleeding was observed after 2 years mean follow-up. One patient deceased due to pulmonary tromboembolism. These results indicate that this method is effective in preventing early and late rebleeding of otherwise unclippable aneurysms.

\section{Illustrative cases}

Case 1 - A 45 years-old lady sought medical attention due to a sudden headache. At neurological examination, she was alert scoring 15 at Glasgow Coma Scale (GCS). Besides meningismus, no abnormalities were noticed. CT scan revealed SAH and angiogram displayed a multilobulated PICA aneurysm that was treated using the clip- wrap technique (Rayon TM), since the parent artery arose from one of the lobulations precluding direct clipping. Postoperative period was uneventful.

Case 2 - A 73 years-old alcoholic male, with previous history of transient ischemic attacks and diagnosis of a fusiform middle cerebral artery aneurysm (Fig 1A), presented to the emergency room complaining of headache. At examination, he was confuse and with neck stiffness. He had been treated of a pulmonary and thyroid carcinomas and presented hepatic cirrhosis. CT scan revealed $\mathrm{SAH}$. Considering the previous history, a clip- wrap technique was performed. Figure $1 \mathrm{~B}$ and Figure $1 \mathrm{C}$ illustrate and detail the surgical technique. Postoperatively, patient presented gastro-intestinal bleeding secondary to esophageal venous ectasia and pulmonary tromboembolism and deceased.

Case 3 - A 75 years-old female, with previous history of chronic arterial hypertension, was brought to the emergency room with history of have been found confuse and complaining of headache. CT scan revealed SAH. Angiogram showed a fusiform aneurysm on the left internal carotid artery, on the supraclinoid segment, and a berry aneurysm on the anterior communicating artery (Fig 2A). Patient was submitted to a clip on ACA aneurysm and clip-wrap procedure on the fusiform ICA aneurysm, once perforator arteries emerge from that segment

Table. Summary of aneurysms treated with the clip-wrap technique.

\begin{tabular}{ccccc}
\hline Case & Age / Gender & $\begin{array}{c}\text { Aneurysm } \\
\text { location }\end{array}$ & Rebleeding & Follow-up \\
\hline 1 & $73 /$ Male & MCA & No & 1 Month \\
2 & $53 /$ Female & MCA & No & 3 Years \\
3 & $75 /$ Female & AchA & No & 1 Year \\
4 & $55 /$ Female & AcomA & No & 3 Years \\
5 & $47 /$ Female & COpht & No & 3 Years \\
6 & $43 /$ Female & COpht & No & 3 Years \\
7 & $40 /$ Female & COpht & No & 3 Years \\
8 & $50 /$ Female & CPA & No & 1 Year \\
9 & $45 /$ Female & PICA & No & 3 Years \\
\hline
\end{tabular}

MCA: middle cerebral artery; AchA: anterior choroidal artery; AcomA: anterior communicating artery; COpht: carotid ophthalmic artery; CPA: cerebral posterior artery; PICA: posterior inferior crebellar artery. 

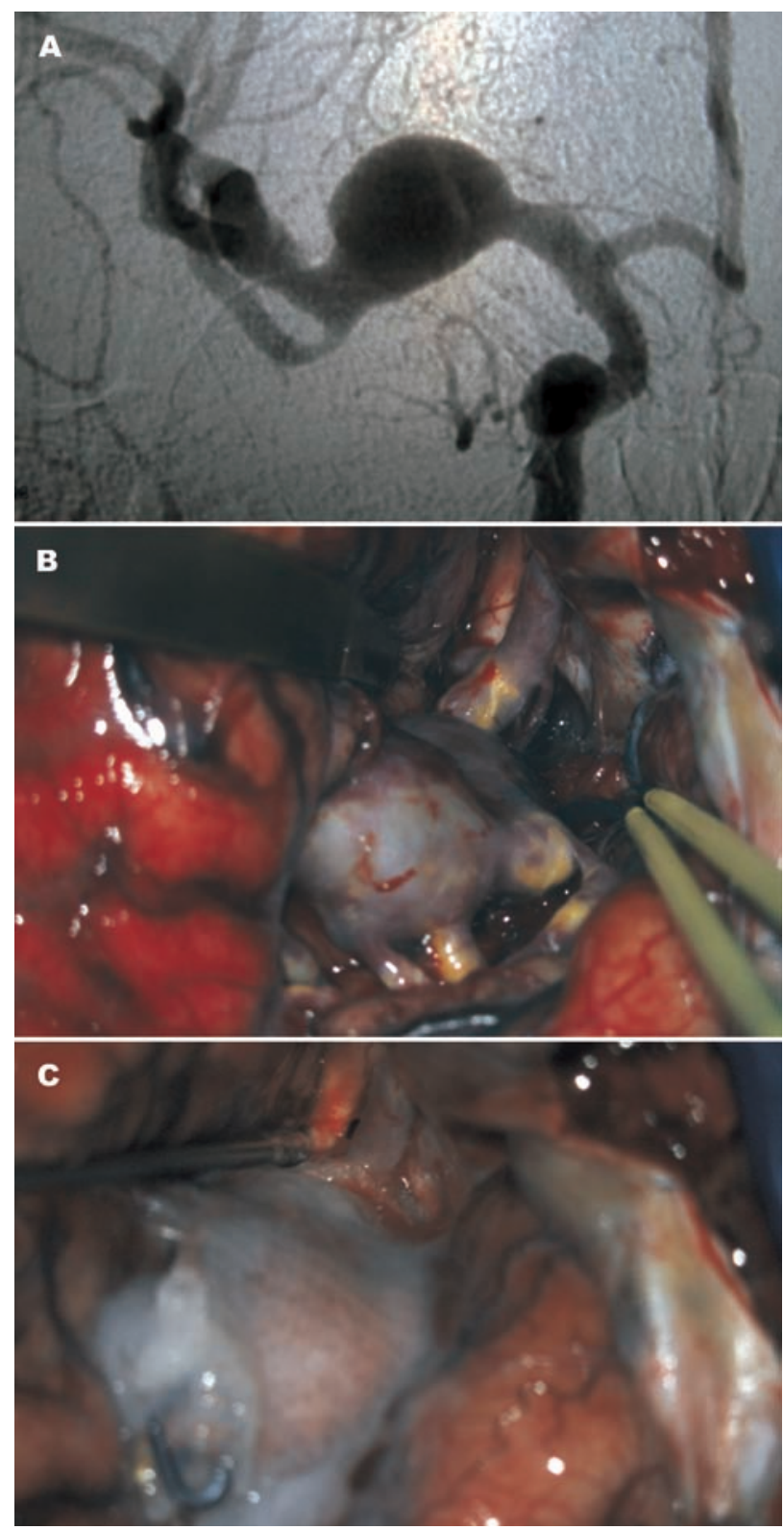

Fig 1. [A] Angiogram demonstrates a large fusiform MCA aneurysm. Frontal view. [B] Microsurgical view. Sylvian fissure has been split and the lesion has been exposed. [C] Microsurgical view. The fusiform segment was dissected after identifying perforators. Next the fusiform aneurysm was wrapped with rayon and fibrin glue was applied.

(Fig 2B and Fig 2C). Patient evolved with vasospasm successfully treated with the $3 \mathrm{H}$ therapy.

\section{DISCUSSION}

Wrapping technique has been used to treat unclippable aneurysms for decades, however in the microsurgical age only a handful studies have been published. Fujiwara et al. ${ }^{1}$ treated ruptured aneurysms with wrapping with $17 \%$ of the cases bleeding within three years of surgery. These data have showed that wrapping reduces the
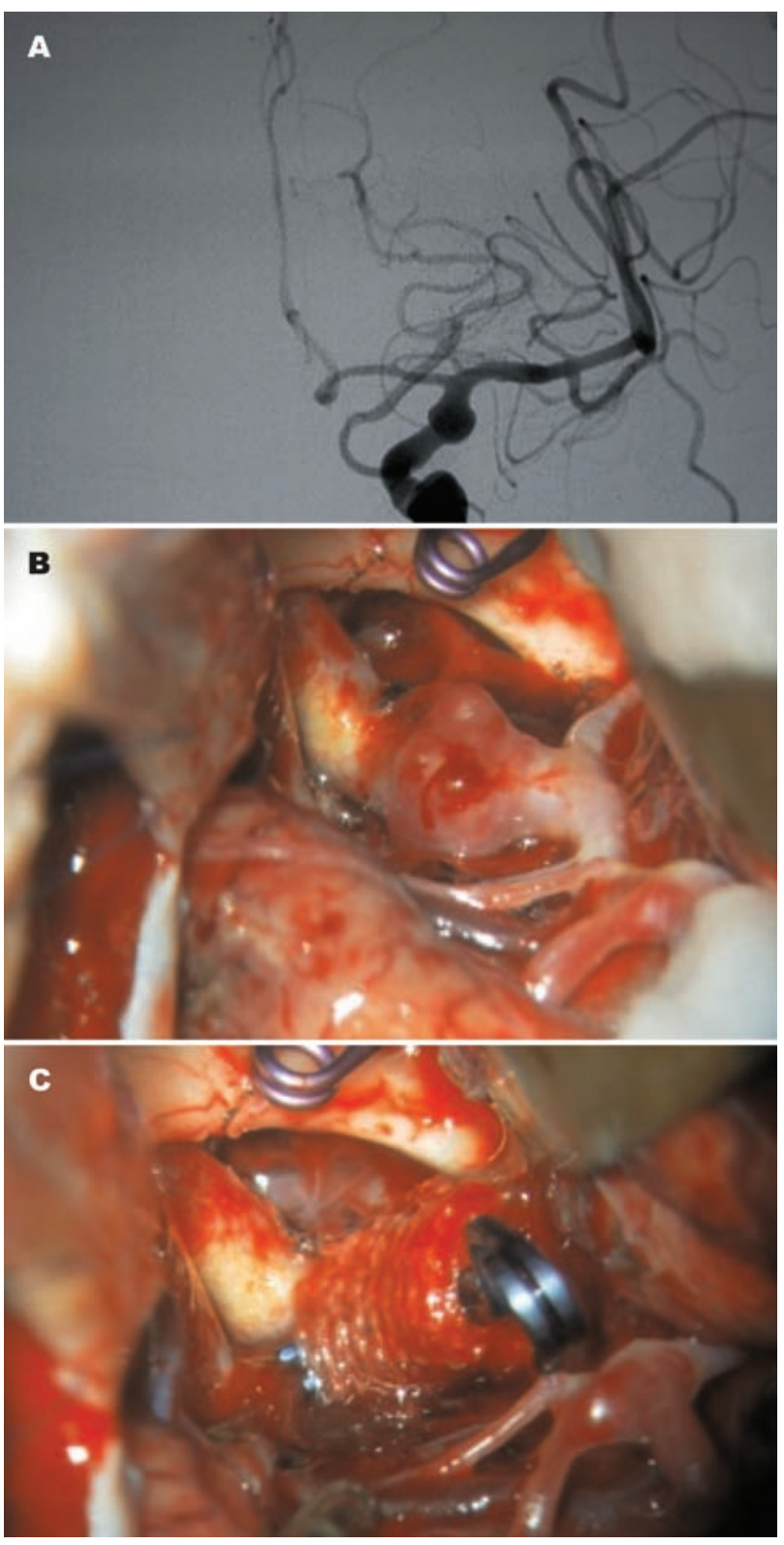

Fig 2. [A] Preoperative angiogram shows a fusiform aneurysm compromising the anterior choroidal artery segment of the internal carotid artery. Frontal view. [B] Operative view of the aneurysm after microsurgical dissection and clipping of an AcomA aneurysm. [C] The lesion has been circumferentially dissected, perforators have been exposed and aneurysm has been wrapped using Rayon.

risk of hemorrhage but with inferior results comparing with clip ligation. One study has showed that the late risk of re-hemorrhage was $1.5 \%$ per year after wrapping ${ }^{2}$. Minakawa et al. ${ }^{3}$ treated 23 ruptured aneurysms by coating them with Biobond and Aron Alpha. Rebleeding occurred in six patients at a mean interval of 4 years. They stated that coating ruptured aneurysms provided no protection against re-hemorrhage.

Ohkuma et al. ${ }^{4}$ used wrapping techniques in seven patients with ruptured dissecting ICA aneurysms. Three 
patients evolved with aneurysmal growth or hemorrhage. Cudlip et al. ${ }^{5}$ presented 15 patients with a solitary ruptured aneurysm treated by wrapping. No patients had rehemorrhaged after one year of follow-up. These results suggest that wrapping ruptured intracranial aneurysms represents a significant advance compared with the natural history of these unclippable lesions.

Deshmukh et al. reported their experience with 63 patients submitted to the clip-wrap technique ${ }^{6}$. Their results point out that wrapping or clip-wrap of unclippable aneurysms may be protective against aneurysmal growth or hemorrhage with low risks of long-term complications, including granuloma formation or arachnoiditis.

Several agents and wrapping techniques have been used $^{6}$. The agents include cotton, muscle, silastic sheet, gauze, Teflon, adhesives (Biobond, fibrin glue, and polyglactin 910 fibrin sealant), and collagen-impregnated $\mathrm{Da}$ cron fabric (Dupont, Wilmington, DE) ${ }^{6}$. No study has examined the relative efficacy of these agents. However, high rate of re-hemorrhage has been reported after using Biobond ${ }^{3}$.

One study has evaluated the histological changes that follow wrapping. Herrera et al. ${ }^{7}$ found that Biobond induced chronic inflammatory changes, necrosis of the media, and luminal narrowing from fibrosis in both the media and adventitia in a rat arterial model. Cotton evoked chronic inflammation, fibrosis, and granuloma formation in the adventitia, but no changes were observed in the media $^{6,7}$. Fibrin glue had been absorbed at two months, but mild inflammation remained in the adventitia ${ }^{6,7}$. These findings demonstrate that cotton may be the prefential agent because it causes an intermediate inflammatory reaction ${ }^{6,7}$.

Our preferred technique is wrapping the aneurysm with Rayon ${ }^{\mathrm{TM}}$, as illustrated by these cases. The fusiform artery should be careful and circumferentially dissected. Every effort must be performed to assure that all perforating vessels are individualized and that no vessel is inadvertently incorporated in the wrap ${ }^{6}$. Next the Rayon ${ }^{\mathrm{TM}}$ strip is wrapped around the aneurismal segment and it is firmly clipped around the artery to ensure that some tension is exerted on the arterial wall. Alternatively, biological glue is applied to guarantee that the Rayon ${ }^{\mathrm{TM}}$ will not be displaced.

The most frequent delayed complication is granuloma in the region of wrapping which may provoke cranial neuropathy ${ }^{6}$. Visual loss and oculomotor nerve palsy have been reported after gauze wrapping of anterior circulation aneurysms ${ }^{8,9}$. McFadzean et al. ${ }^{10}$ described five cases of optochiasmic arachnoiditis after muslin wrapping of anterior communicating artery aneurysms. The wrapping agent should then not be placed in direct contact with cranial nerves.

In summary, clip-wrap techniques for the treatment of fusiform and otherwise unclippable aneurysms seem to be safe and it can be associated with a low rate of acute or delayed postoperative complications. It can prevent rebleeding and growth of these lesions and represents an improvement when compared with the natural history of such complex aneurysms.

\section{REFERENCES}

1. Fujiwara S, Fujii K, Nishio S, Fukui M. Long-term results of wrapping of intracranial ruptured aneurysms. Acta Neurochir (Wien) 1990;103:27-29.

2. Todd NV, Tocher JL, Jones PA, Miller JD. Outcome following aneurysm wrapping: A 10-year follow-up review of clipped and wrapped aneurysms. J Neurosurg 1989;70:841-846.

3. Minakawa T, Koike T, Fujii Y, Ishii R, Tanaka R, Arai H. Long term results of ruptured aneurysms treated by coating. Neurosurgery 1987;21:660-663.

4. Ohkuma H, Nakano T, Manabe H, Suzuki S. Subarachnoid hemorrhage caused by a dissecting aneurysm of the internal carotid artery. J Neurosurg 2002;97:576-583.

5. Cudlip SA, Kitchen ND, McKhahn GM, Bell BA. Wrapping of solitary ruptured intracranial aneurysms, outcome at five years. Acta Neurochir(Wien) 1998;140:1167-1170.

6. Deshmukh VR, Kakarla UK, Figueiredo EG, Zabramski JM, Spetzler RF. Longterm clinical and angiographic follow-up of unclippable wrapped intracranial aneurysms. Neurosurgery 2005;58:434-442.

7. Herrera O, Kawamura S, Yasui N, Yoshida Y. Histological changes in the rat common carotid artery induced by aneurysmal wrapping and coating materials. Neurol Med Chir (Tokyo) 1999;39:134-139.

8. Carney PG, Oatey PE. Muslin wrapping of aneurysms and delayed visual failure. A report of three cases. J Clin Neuroophthalmol 1983;3:91-96.

9. Onoue H, Abe T, Tashibu K, Suzuki T. Two undesirable results of wrapping of an intracranial aneurysm. Neurosurg Rev 1992;15:307-309.

10. McFadzean RM, Hadley DM, Mcllwaine GG. Optochiasmal arachnoiditis following muslin wrapping of ruptured anterior communicating artery aneurysms. J Neurosurg 1991;75:393-396. 